\title{
HPV infection in Brazilian oral squamous cell carcinoma patients and its correlation with clinicopathological outcomes
}

\author{
LUCINEI ROBERTO OLIVEIRA ${ }^{1}$, ALFREDO RIBEIRO-SILVA ${ }^{1}$, LEANDRA NAIRA ZAMBELLI RAMALHO ${ }^{1}$, \\ AGUINALDO LUIZ SIMÕES ${ }^{2}$ and SERGIO ZUCOLOTO ${ }^{1}$
}

\begin{abstract}
Departments of ${ }^{1}$ Pathology, and ${ }^{2}$ Genetics, Ribeirao Preto Medical School, University of Sao Paulo,
\end{abstract} Ave. Bandeirantes 3900, 14049-900. Ribeirao Preto/SP, Brazil

Received November 2, 2007; Accepted December 3, 2007

\begin{abstract}
This study aims to investigate human papilloma virus (HPV) frequency in Brazilian patients with oral squamous cell carcinoma (OSCC) in order to establish a clinicopathological profile. It will also examine the correlation between patient survival and HPV expression in primary tumors (PTs), and their matched samples (MSs) of recidives, lymph nodal metastasis (LNM) or necropsies. Eighty-seven PTs and their corresponding $87 \mathrm{MSs}$ were tested for HPV infection by polymerase chain reaction (PCR) using general and type-specific HPV primers. The following data were obtained from patient medical files: primary site, age, gender, tobacco consumption, histological differentiation, recurrences, metastasis, disease-free survival (DFS) and overall survival (OS). Of the 87 patients investigated, 17 (19.5\%) were found to have HPV DNA in their tumors. An investigation of all the paraffin-embedded specimens revealed the presence of HPV DNA in 18 of the 174 samples $(10.4 \%), 10(11.5 \%)$ from PTs and $8(9.2 \%)$ from MSs. No virus was detected in the corresponding PT of 7 (8.1\%) MSs, and only one patient demonstrated HPV DNA positivity in both samples. The HPV genotypes 16 and 18 were detected in $4(22.2 \%)$ and $3(16.7 \%)$ of the positive samples, respectively. Infection with both genotypes was found in 6 $(33.3 \%)$ investigated samples, and the HPV genotype was unidentified in $5(27.8 \%)$ samples. The tongue was the most prevalent infected anatomical site. We did not find any significant association between HPV infection and gender, age, histological differentiation, DFS or OS. A significant number of HPV samples were positive among non-smoking patients. Although a possible influence of the virus on tumoral induction cannot be ruled out, the low frequency of OSCC cases that contain HPV does not suggest that this virus has the same etiological influence on patients as tobacco consumption does.
\end{abstract}

Correspondence to: Dr Lucinei Roberto Oliveira, Department of Pathology, Ribeirao Preto Medical School, University of Sao Paulo, Ave. Bandeirantes 3900, 14049-900. Ribeirao Preto/SP, Brazil E-mail: lucinei@yahoo.com

Key words: oral cancer, HPV, oral squamous cell carcinoma, tobacco, prognosis

\section{Introduction}

Oral squamous cell carcinoma (OSCC) is the sixth most common malignancy worldwide. The overall survival (OS) has not changed in recent years, despite extensive research on its biological and molecular characteristics. The main problems in the clinical management of this malignancy are the high incidence of local-regional recurrence and the lack of early detection (1).

Tobacco and alcohol are well-established risk factors for OSCC, but it can also develop in individuals who have never smoked (2). Moreover, only a small proportion of tobaccoexposed individuals have developed OSCC, and there is an emerging tumoral population who lack exposure to the mentioned risk factors $(3,4)$, suggesting that others factors can play a role in oral carcinogenesis.

Over the past 2 decades, the role of high-risk human papilloma virus (HPV) has been studied, and data supporting its role as a causative agent in the development and progression of a subset of OSCC has been controversial, with considerable variability in frequency depending on the population studied, tumor localization, quality of samples and technical resources utilized for HPV detection (5-7).

As is the case in cervical and anogenital carcinomas, the most frequently detected high-risk HPVs in OSCC were the 16 and 18 genotypes (4). High-risk HPV infection tends to be more persistent, and has been associated with tumoral recurrence episodes after surgical therapy in cervical carcinomas, which affects disease prognosis (8).

Evidence from several laboratories demonstrates that highrisk HPVs are involved in the etiology of OSCC. These data indicate that oral keratinocytes can be transformed with highrisk HPVs in vitro through mechanisms involving viral oncoproteins $(9,10)$. Moreover, in some cases the HPV genotype identified in primary OSCC is maintained in nodal metastases $(11,12)$.

In several later studies, HPV DNA was detected by methods such as polymerase chain reaction (PCR), Southern blotting and in situ hybridization in the sera and tumor tissue of OSCC patients $(5,13)$, confirming previous data. Nowadays, PCR is considered the most sensitive method for the detection of HPV DNA in clinical specimens (14).

In a meta-analysis study including 4680 OSCC samples from 94 reports, the overall level of HPV prevalence in OSCC 
was $46.5 \%$, in contrast to $10 \%$ in normal oral mucosa reported in 27 analyzed data sets. Moreover, high-risk HPVs were significantly more likely to be detected in OSCC specimens than low-risk HPVs (1).

The presence of HPV in OSCC has been investigated in different populations. Differences among the various populations were identified, with trends of higher frequencies in some population groups. In a study performed with a Mexican population, Ibieta et al found that $42 \%$ of their samples were HPV positive (15). In another investigation, conducted with Indian patients, Balaram et al found a high prevalence (75\%) and multiplicity of HPV infections (3). Moreover, a 100\% prevalence was found in a mixed Japanese/Chinese population (16). On the other hand, in a recent study with a Brazilian population, Rivero and Nunes found the complete absence of HPV DNA in the 17 fresh and 23 paraffin-embedded tissues that were evaluated (17).

The purpose of the present study was to investigate the presence of HPV in a Brazilian population sample of OSCC patients. Additionally, in cases with positive specimens, analysis was extended to clinicopathological profile characterization and to the correlation between patient survival and the presence of HPV DNA in primary OSCC tumors and in their corresponding matched samples (MSs) of recurrences, lymph nodal metastasis (LNM) and necropsies.

\section{Materials and methods}

Patients and samples. This study population is from two other previous studies, recently performed at our laboratories, focused on the prognostic factors associated with OSCC $(18,19)$. Research was conducted on the medical files of patients with head and neck tumors, the histopathological diagnosis of OSCC was confirmed and paraffin-embedded specimens were selected.

The medical files were analyzed and reviewed in order to collect information concerning the age, gender, primary tumor site, tobacco exposure, metastasis, tumoral recurrences, histological grade classification, disease-free survival (DFS) and OS of the patients.

Following the collection of information from the medical files, the inclusion criteria for this study were applied, including: a) adequate clinicopathological data; b) availability of sufficient paraffin-embedded tumor material; c) presence of oral cavity cancer (including oral tongue, floor of mouth, gingiva, lips, buccal mucosa, hard palate and retromolar trigone) (20); d) no previous head and neck cancer; e) no prior oncological therapy; f) histologically-proven squamous cell carcinoma; g) a single lesion; h) absence of initial or distant metastasis. Patients with in situ and/or T4 tumors were excluded from this study.

Patients were classified as never, current or former daily (those who had quit for more than 12 months before diagnosis) tobacco smokers, and whether they smoked cigarettes, a pipe and/or cigars was taken into consideration (5).

Tumoral recurrence was defined as the occurrence of another carcinoma $<2 \mathrm{~cm}$ away from the primary carcinoma (21). Tumors were classified as well- moderately- or poorlydifferentiated according to the World Health Organization classification of histological differentiation grade (22). The
DFS was defined as the interval between the beginning of the treatment and the date of the first recurrence (local recurrence or metastasis) or last follow-up. The OS was defined as the interval between the beginning of treatment and the date of death or the last follow-up.

For the evaluation of possible HPV DNA tumoral persistence, two samples from each patient were investigated: primary tumor (PT) was selected as the initial sample and tumoral recurrence, LNM and necropsy occurrences were used as the corresponding MSs. For the MSs, the selected tumoral recurrence was taken from the same anatomical region $(<2 \mathrm{~cm}$ away), the LNM from the most representative tumoral area and the necropsy specimens from irresectable tumors. The paraffin-embedded specimens with the highest tumoral area were selected for DNA analysis.

After surgical resection, the tumor tissues were routinely fixed in $4 \%$ neutral-buffered formalin, embedded in paraffin blocks and archived according to institution protocol. Later, the selected paraffin-embedded specimens were retrieved and processed to $5-\mu \mathrm{m}$ thick sections, stained with hematoxylineosin and reviewed by two medical pathologists (A.R.S. and S.Z.) to confirm the diagnosis and the histological classification grade.

One hundred and seventy-four paraffin-embedded specimens, 87 PTs and $87 \mathrm{MSs}$, that corresponded to the biopsy or surgical resection of 87 patients with histologically-confirmed primary OSSC were selected from the files of the Department of Pathology of the Ribeirao Preto School of Medicine General Hospital, University of Sao Paulo, Brazil, from 1990 to 2002. These specimens were sliced into $5-\mu \mathrm{m}$ thick sections and processed for DNA extraction. To prevent cross-contamination, the microtome blade was discarded after each block was sectioned, and the sections from the selected specimens were transferred to sterile $1.5-\mathrm{ml}$ tubes with tweezers.

The study protocol was integrally approved by the local Ethics Committee according to HC-FMRP 7327/ 2004 process.

DNA isolation and internal control amplification. DNA was isolated from formalin-fixed paraffin-embedded tissue specimens with a Promega Tissue Kit according to the manufacturer's instructions (MagneSil ${ }^{\circledR}$ Genomic, Fixed Tissue System, Promega Corp., Madison, WI, USA). The DNA solutions were stored at $-20^{\circ} \mathrm{C}$.

DNA integrity and the absence of PCR inhibitors were verified by the amplification of a 110-bp fragment of the ubiquitous human $B$-globin gene (23). The primers were PC03 (5'-ACACAACTGTGTTCACTAGC-3') and PC04 (5'-CAA CTTCATCCACGTTCACC-3') (Bioneer Inc., Daejeon, Korea) (24). Only samples with a visible B-globin band were included in this study. When a sample was negative for B-globin, an additional section was taken from the block and re-analyzed. Successful amplification of the $\beta$-globin gene fragment indicated that the DNA sample was adequate for HPV DNA analysis.

HPV DNA detection. We utilized the $\mathrm{GP}^{+} / \mathrm{GP}^{+}$(Bioneer Inc.) consensus general primer pair to amplify a 150-bp fragment from the L1 gene of general HPV types $\left(\mathrm{GP}^{+}, 5^{\prime}\right.$-TTTGTTA CTGTGGTAGATACTAC-3'; GP6+', 5'-GAAAAATAAACT GTAAATCATATTC-3') (25). 
Table I. Demographics and clinical features according to tumor localization of the studied Brazilian patients with OSCC (\%).

\begin{tabular}{|c|c|c|c|c|c|c|}
\hline & \multicolumn{6}{|c|}{ Primary site } \\
\hline & Floor & Tongue & Hard palate & Lower lip & Others $^{\mathrm{a}}$ & Total \\
\hline Cases & $26(29.9)$ & $22(25.3)$ & $17(19.5)$ & 13 (14.9) & $9(10.4)$ & 87 (100) \\
\hline \multicolumn{7}{|l|}{ Age } \\
\hline$\leq 60$ years & $21(80.8)$ & $13(59.1)$ & $10(58.8)$ & $6(46.2)$ & $4(44.4)$ & $54(62.1)$ \\
\hline$\geq 60$ years & $5(40.9)$ & $9(40.9)$ & 7 (41.2) & $7(53.8)$ & $5(55.6)$ & 33 (37.9) \\
\hline \multicolumn{7}{|l|}{ Gender } \\
\hline Male & $24(92.3)$ & $16(72.7)$ & $15(88.2)$ & $11(84.6)$ & $7(77.8)$ & $73(83.9)$ \\
\hline Female & $2(7.7)$ & $6(27.3)$ & $2(11.8)$ & $2(15.4)$ & $2(22.2)$ & $14(16.1)$ \\
\hline \multicolumn{7}{|l|}{ Recurrence } \\
\hline No & $13(50)$ & $8(36.4)$ & $8(47.1)$ & $7(53.9)$ & $4(44.4)$ & $40(46)$ \\
\hline Yes & $13(50)$ & $14(63.6)$ & $9(52.9)$ & $6(46.1)$ & $5(55.6)$ & $47(54)$ \\
\hline \multicolumn{7}{|l|}{ Metastasis } \\
\hline No & $14(53.9)$ & $15(68.2)$ & $10(58.8)$ & $6(46.1)$ & $5(55.6)$ & $50(57.5)$ \\
\hline Yes & $12(46.1)$ & $7(31.8)$ & $7(41.2)$ & $7(53.9)$ & $4(44.4)$ & $37(42.5)$ \\
\hline \multicolumn{7}{|l|}{ Death } \\
\hline No & $17(65.4)$ & $11(50)$ & $11(64.7)$ & $10(76.9)$ & $5(55.6)$ & $54(62.1)$ \\
\hline Yes & $9(34.6)$ & $11(50)$ & $6(35.3)$ & $3(23.1)$ & $4(44.4)$ & 33 (37.9) \\
\hline
\end{tabular}

${ }^{a}$ Others anatomical sites include the retromolar trigone, buccal mucosa, gingiva and upper lip.

PCR was then performed on the HPV-positive DNA samples, to determine if they contained genotypes 16 and 18, using specific primers targeting $\sim 100$ bp in the E7 ORF: HPV-16E7.667 (5'-GATGAAATAGATGGTCCAGC-3'), HPV-16E7.774 (5'-GCTTTGTACGCACAACCGAAGC-3'), HPV-18E7.696 (5'-AAGAAAACGATGAAATAGATG GA-3') and HPV-18E7.799 (5'-GGCTTCACACTTACAAC ACA-3') (Bioneer Inc.) (26).

Polymerase chain reaction. Amplifications of general HPV genotypes and B-globin DNA were done in the same reaction. A PCR test was performed on each microtube, which contained $5 \mu 1$ of extracted genomic DNA and the addition of a mixture reaction containing 12.5 $\mu \mathrm{l}$ PCR Master Mix ${ }^{\circledR}$ (Promega Corp.), $1.2 \mu 1$ PC03/PC04 primer, $4.3 \mu 1 \mathrm{GP}^{+} / \mathrm{GP}^{+}$ primer and $2.0 \mu \mathrm{l}$ sterile water, for a total volume of $25 \mu \mathrm{l}$, and one mineral oil drop added to the surface of the mixture. The primers were added to a final concentration of $50 \mu \mathrm{M}$. In the detection of specific HPV subtypes, the PCR mixture contained $5 \mu 1$ DNA sample, $12.5 \mu 1$ PCR Master Mix (Promega Corp.), $2 \mu 1 \mathrm{HPV}-16 \mathrm{E} 7$ or HPV-18E7 primers and 5.5 $\mu 1$ sterile water.

For HPV general and specific genotype detection, PCR was performed with forty amplification cycles in a thermocycler (PTC-100 ${ }^{\text {тм }}$, MJ Research, Watertown, MASS, USA) as follows: 1 cycle at $95^{\circ} \mathrm{C}$ x 5 min for initial denaturation, annealing at $53^{\circ} \mathrm{C} \times 2 \mathrm{~min}$, chain elongation at $72^{\circ} \mathrm{C} \times 2 \mathrm{~min}$, and 39 subsequent cycles at $94^{\circ} \mathrm{C} \times 1$ min for denaturation, annealing at $51^{\circ} \mathrm{C} \times 2$ min and chain elongation at $72^{\circ} \mathrm{C} \times$ $2 \mathrm{~min}$. A final extension of $72^{\circ} \mathrm{C}$ for 10 min followed the last cycle. As a positive control for the PCR protocol of HPV-16 and HPV-18 genotypes, serial 1:10 dilutions with $5 \mu 1 \mathrm{SiHa}$ and HeLa culture cells was performed in each experiment. For general HPV detection, a dilution mixture with both positive controls was realized. Positive controls always produced amplimers of the correct size. As a negative control, sterile water was utilized in place of the 5- $\mu 1$ DNA sample. To avoid false-positive results, all known precautions to avoid a PCR product carry-over and sample-to-sample contamination were rigorously carried out. Different steps of the PCR procedure were performed in separate rooms with different pipettes. None of the negative control samples were positive in any of the HPV assays.

DNA analysis. To characterize the amplified products, the samples were analyzed by electrophoresis in vertical gels of $8 \%$ non-denaturing polyacrylamide. They were subjected to electrophoretic conditions of $200 \mathrm{~mA}$ constantly for a 2-h period, and were stained with $\mathrm{AgNO}_{3}$ according to the method reported by Bettini et al (26). A 50-bp DNA ladder (Biotools, B\&M Labs, Madrid, Spain) was used as size marker.

Statistical analysis. GraphPad Prism 4.0 for Windows (GraphPad Software, San Diego, CA, USA) was used for all statistical analyses. Descriptive statistics were used to summarize the study data. The $\chi^{2}$ test was performed for statistical comparisons of the categorical variables between groups. Kaplan-Meier curves were used for the graphical representation of survival and the log-rank test was used to 
Table II. HPV infection characteristics obtained from the 17 HPV-positive Brazilian patients with OSCC in their two studied samples.

\begin{tabular}{|c|c|c|c|c|c|c|c|}
\hline \multirow[b]{2}{*}{ No. } & \multirow[b]{2}{*}{ Age } & \multirow[b]{2}{*}{ Gender } & \multirow[b]{2}{*}{ Tobacco use ${ }^{a}$} & \multirow[b]{2}{*}{ PT } & \multirow[b]{2}{*}{ MS } & \multicolumn{2}{|c|}{ Differentiation $^{\mathrm{b}}$} \\
\hline & & & & & & PT & MS \\
\hline 1 & 60 & $\mathrm{~F}$ & Non-smoker & Tongue $^{c}$ & Recurrence $^{c}$ & $\mathrm{~W}$ & $\mathrm{M}$ \\
\hline 2 & 54 & M & Smoker & Tongue & Recurrence ${ }^{g}$ & $\mathrm{~W}$ & $\mathrm{~W}$ \\
\hline 3 & 60 & M & Smoker & Tongue $^{e}$ & Recurrence & $\mathrm{W}$ & W \\
\hline 4 & 61 & $\mathrm{~F}$ & Non-smoker & Tongue $^{\mathrm{d}}$ & Recurrence ${ }^{g}$ & $\mathrm{M}$ & $\mathrm{W}$ \\
\hline 5 & 90 & $\mathrm{~F}$ & Non-smoker & Tongue $^{\mathrm{d}}$ & Recurrenceg & $\mathrm{W}$ & W \\
\hline 6 & 53 & M & Smoker & Floor $^{\mathrm{g}}$ & Recurrence $^{c}$ & $\mathrm{~W}$ & W \\
\hline 7 & 53 & M & Non-smoker & Floor $^{\mathrm{e}}$ & Recurrenceg & $\mathrm{M}$ & M \\
\hline 8 & 57 & M & Smoker & Floor $^{\mathrm{g}}$ & Metastasis $^{\mathrm{f}}$ & $\mathrm{W}$ & W \\
\hline 9 & 46 & M & Smoker & Floor $^{\mathrm{g}}$ & Metastasis & $\mathrm{W}$ & W \\
\hline 10 & 62 & M & Smoker & Lower lip ${ }^{\mathrm{e}}$ & Recurrence ${ }^{\mathrm{g}}$ & $\mathrm{W}$ & $\mathrm{W}$ \\
\hline 11 & 71 & M & Smoker & Lower lipg & Metastasis $^{\mathrm{f}}$ & $\mathrm{W}$ & W \\
\hline 12 & 71 & $\mathrm{~F}$ & Non-smoker & Lower lipg & Recurrence $^{c}$ & $\mathrm{M}$ & $\mathrm{P}$ \\
\hline 13 & 59 & M & Non-smoker & Hard palate $^{f}$ & Recurrence & $\mathrm{M}$ & M \\
\hline 14 & 57 & M & Smoker & Hard palate $^{f}$ & Recurrence & $\mathrm{W}$ & M \\
\hline 15 & 47 & M & Non-smoker & Hard palate $^{\mathrm{e}}$ & Metastasis & $\mathrm{W}$ & M \\
\hline 16 & 50 & M & Smoker & Hard palate & Recurrence $^{\mathrm{d}}$ & $\mathrm{W}$ & M \\
\hline 17 & 53 & M & Smoker & Retromolar & Necropsy $^{\mathrm{f}}$ & $\mathrm{P}$ & $\mathrm{P}$ \\
\hline
\end{tabular}

$\mathrm{M}$, male; F, female; PT, primary tumor; MS, matched sample. ${ }^{\mathrm{a}}$ According to Gillison et al (5). ${ }^{\mathrm{b}}$ Histological differentiation according to the

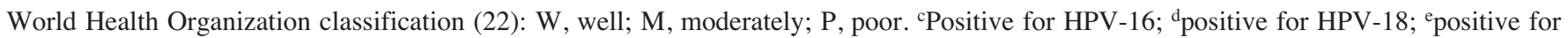
both; ${ }^{\mathrm{f}} \mathrm{HPV}$ subtype was not identified; ${ }^{\mathrm{H}} \mathrm{HPV}$ DNA absent.

analyze significant differences in survival curve comparisons (27). Analysis was computed by comparing the HPV positive or negative tumors. Survival data were censored for patients that were alive at the last follow-up. In addition, the survival data were censored for those patients with no recurrence of DFS. Statistical significance was defined as a two-tailed P-value $\leq 0.05$.

\section{Results}

Patient age varied between 46-90 years (mean, 59). Clinical data from the study population are summarized in Table I.

For each patient, two samples were analyzed, one from the PT and the other from the corresponding MS. The investigated MS samples consisted of 49 tumoral recurrences, 28 LNMs and 10 necropsies.

Internal control amplification with $\beta$-globin primers $\mathrm{PC} 03 /$ PC04 showed amplifiable DNA in all 174 paraffin-embedded specimens studied. General amplification with the HPV L1 $\left(\mathrm{GP}^{+} / \mathrm{GP}^{+}\right)$consensus primer pair showed the presence of HPV DNA in 18 of the $174(10.4 \%)$ specimens and in 17 of the $87(19.5 \%)$ studied patients (Table II). The HPV-positive control was amplified in all reactions.

There was HPV DNA positivity in 10 of the 87 (11.5\%) PT-analyzed samples. In the MSs, HPV DNA was identified in 8 of 87 (9.2\%) paraffin-embedded OSCC specimens; 4 (4.6\%) were tumoral recurrences, 3 (3.5\%) LNM and $1(1.1 \%)$ necropsy. Of the MSs, 7 (8.1\%) were without viral detection in their corresponding PTs, and only one patient demonstrated HPV DNA positivity in both samples (Table II). The tongue was the most prevalent anatomical site for HPV DNA positivity followed by the hard palate, which had $6(33.3 \%)$ and 4 (22.2\%) of the 18 positive paraffin-embedded specimens, respectively.

The presence of HPV-16 and -18 genotypes was detected in $4(22.2 \%)$ and $3(16.7 \%)$ of the 18 OSCC HPV positive-testing paraffin-embedded specimens, respectively. Both genotypes were found in $6(33.3 \%)$ samples and the HPV genotype was not identified in $5(27.8 \%)$ of them (Table II).

The HPV DNA-positive OSCC patients consisted of 13 males and 4 females, with a male-female ratio of 3.25:1. However, the HPV positivity rate of males was lower than that of females (17.8 vs. 28.6\%). Both the investigated samples from one female patient were positive (PT and MS), and four HPV-positive samples from females were located in the tongue (Table II). However, no significant differences were found when HPV infection was analyzed according to gender (Fig. 1, $\mathrm{P}=0.460$ ) or age (Fig. 2, $\mathrm{P}=0.418$ ).

Histological differentiation was not influenced by the presence of HPV DNA ( $\mathrm{P}=0.296$, Table III), although the majority (12-66.7\%) of the $18 \mathrm{HPV}$-positive specimens were considered histologically well-differentiated (61.1\%). HPVpositive samples were significantly more frequent among nonsmoking patients $(\mathrm{P}=0.013$, Table IV). 


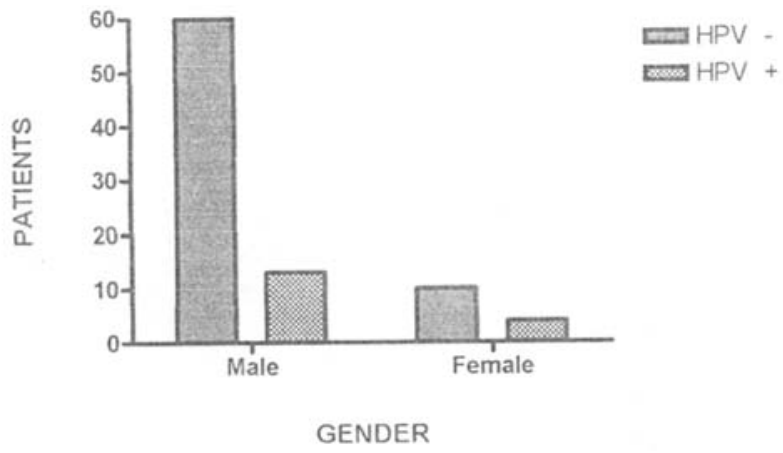

Figure 1. Gender distribution of OSCC patients according to HPV infection.

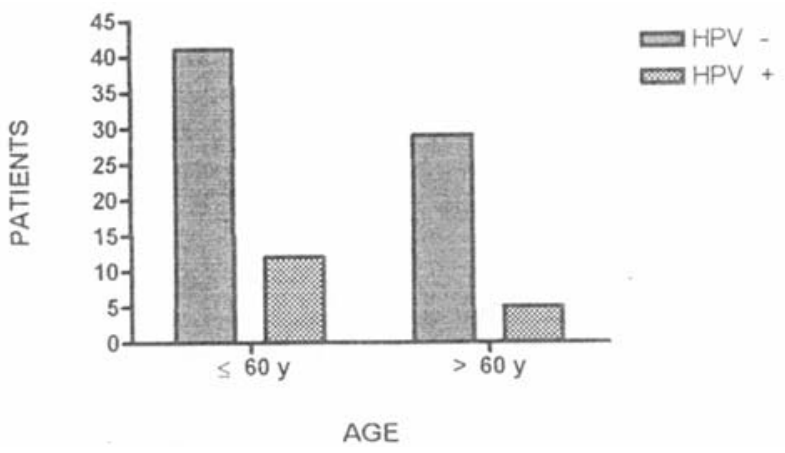

Figure 2. Distribution of OSCC patients according to age and HPV infection.

Table III. OSCC sample distribution according to histological differentiation and HPV positivity (\%).

\begin{tabular}{lrrr}
\hline & HPV & HPV $^{+}$ & Total \\
\hline $\begin{array}{l}\text { Histological } \\
\text { differentiation }\end{array}$ & & & \\
Well & $75(48.1)$ & $12(66.7)$ & $87(50)$ \\
Moderately & $62(39.7)$ & $4(22.2)$ & $66(37.9)$ \\
Poor & $19(12.2)$ & $2(11.1)$ & $21(12.1)$ \\
Total & $156(100)$ & $18(100)$ & $174(100)$ \\
\hline
\end{tabular}

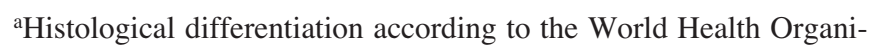
zation classification (22).

The follow-up period ranged from 6 to 118 months (median 20). There were 33 (37.9\%) deaths, 9 in HPV-positive and 24 in HPV-negative patients. The median DFS was 13 months and the 5-year OS 28.6\%. In Kaplan-Meier analyses, even though HPV-negative patients had better survival in the OS and DFS curves, no significant results were found in the survival curve comparisons (OS, $\mathrm{P}=0.859$; DFS, $\mathrm{P}=0.254$ ). HPV-negative patients had a 37 -month median survival and a 5 -year OS of $29.9 \%$. For HPV-positive patients, median survival was 35 months and 5-year OS 28.5\%. Curves for OS and DFS according to HPV DNA status are presented in Figs. 3 and 4, respectively.
Table IV. Tobacco consumption in OSCC patients according to HPV status (\%).

\begin{tabular}{lccc}
\hline & \multicolumn{3}{c}{$\mathrm{HPV}$ status } \\
\cline { 2 - 4 } HABIT $^{\mathrm{H}}$ & $\mathrm{HPV}^{-}$ & $\mathrm{HPV}^{+}$ & Total \\
\hline Smokers & $61(87.1)$ & $10(58.8)$ & $71(81.6)$ \\
Non-smokers & $9(12.9)$ & $7(41.2)$ & $16(18.4)$ \\
Total & $70(100)$ & $17(100)$ & $87(100)$ \\
\hline
\end{tabular}

${ }^{a}$ According to Gillison et al (5).

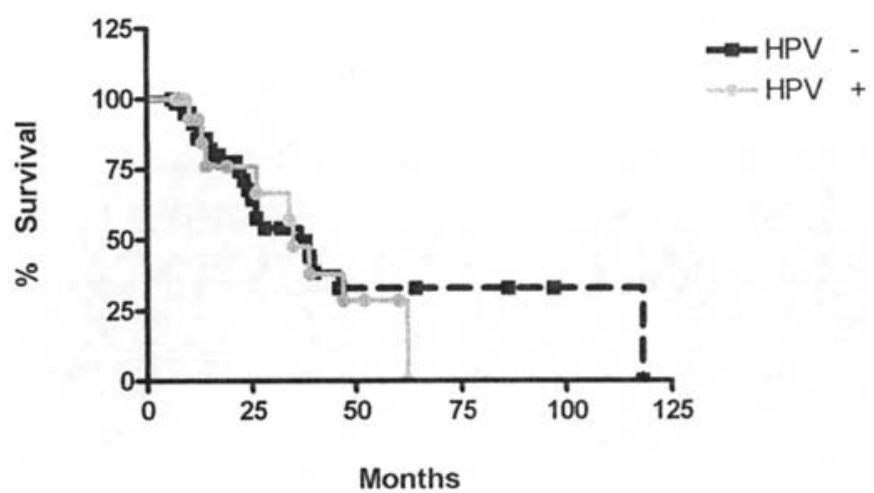

Figure 3. Overall survival according to HPV infection in Brazilian OSCC patients.

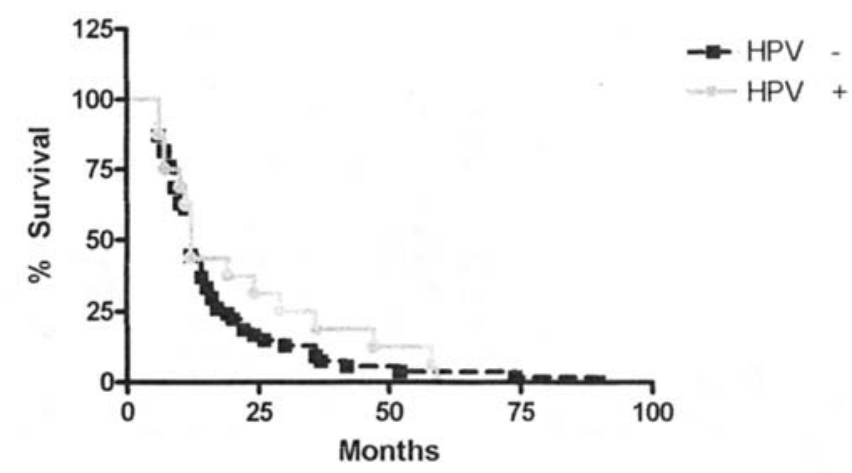

Figure 4. Disease-free survival according to HPV infection in Brazilian oral squamous cell carcinoma patients.

\section{Discussion}

The actual prevalence of HPV DNA in OSCC and its role as a possible oncogenic agent are still controversial. Some authors have pointed out that the occasional finding of HPV DNA in OSCC specimens might not result from viral infection but rather from an incidental HPV colonization of the oral mucosa, and that high infection rates with the presence of more than one HPV genotype could be due to the occurance of opportunistic and cumulative infection by it and other pathological agents 
in the tumoral lesion $(28,29)$. Moreover, high HPV prevalence rates obtained in some studies may have been influenced by false-positive results that led to overestimated infection rates and instigated confusion regarding the etiologic role of HPV in OSCC $(1,17,28)$.

In the 174 OSCC samples tested in our study, the overall positivity rate of $18(10.4 \%)$ is very close to the results reported by Dahlgren et al (7), who studied tongue OSCC (10.9\%). However, their study included mobile and base tongue samples and, considering only the mobile tongue results, our HPVpositive rate (22.7 vs. $2.4 \%$ ) is higher. Our HPV-positive rate is also higher than results found by Kantola et al (30), who detected no HPV presence in the 105 (paraffin-embedded) mobile tongue tumors they analyzed.

Few studies have investigated HPV continuity or reinfection in the tumoral recurrence, LNM or necropsies samples of OSCC $(11,31)$. Similar to results reported by Howell and Gallant (11), we detected HPV-16 in both the PT and MS of only one OSCC case while, in 7 cases, HPV DNA could only be detected in the MS and not in the PT. These findings could suggest that HPV presence is transitory in OSCC progression.

Several reports have proposed a potential role for HPV genotypes associated with a high risk of cervical cancer in the malignant transformation of oral mucosa stem cells $(32,33)$. However, the HPV-16 and -18 individual frequencies we discovered (22.2 and $16.7 \%$, respectively), as well as the dual infection frequency $(33.3 \%)$, were lower than those reported in other investigations $(3,34)$.

In 5 of the $18(27.8 \%)$ tumoral samples, the HPV genotype was not identified. Some authors have previously observed that there is no set of primers that can detect all HPV genotypes, and that most HPV consensus primers are primarily designed to detect the HPV genotypes that are common in cervical samples (35).

Contrary to Cruz et al (36), but in accordance with others $(34,37)$, the HPV-positive sample distribution showed no significant difference in histological differentiation grade classification.

Despite our having the largest number of OSCC male patients of all the studies that have been conducted, the result of a higher rate of HPV-positive occurrence in OSCC females (28.6\%) than males has never been seen before. However, this inverse difference did not reach statistical significance. Most other investigations also included more males than females, but had less women with HPV-positive tumors $(34,38,39)$. Moreover, in contrast to some studies $(1,36,37)$, a significant HPV prevalence in males or patients less than 60 years old could not be detected in our investigation.

The association between HPV status and tobacco consumption reached statistical significance, confirming previous studies that showed HPV infection to be more frequent in non-smokers $(40,41)$. This may occur due to a protective effect of the increased keratinization of the normally parakeratinized mucosal surfaces in smoking patients (42).

Several studies have examined the association between HPV detection in oral and oropharyngeal squamous cell carcinomas and patient survival. However, the results of these investigations have led to different conclusions. A few studies found that HPV-infected OSCC patients have better survival than those with HPV-negative tumors $(38,39,43)$.
Ritchie et al described a possible interaction between HPV infection and gender on survival in oral and oropharyngeal cancers (39). Due to the small number of HPV-positive samples in our study, it was not possible to research this gender association.

We found reduced OS rates and no significant difference in the survival curves (DFS and OS) of HPV-positive and -negative samples. Our results demonstrate a smaller discrepancy between the 5-year OS rates of HPV-positive and -negative tumors (28.5 and $29.9 \%$, respectively) than those of Ritchie et al (39), which indicated a significant difference of 71 and $49 \%$ in HPV-positive and -negative tumors, respectively.

The reported frequency of HPV DNA detection varies considerably between studies. This may be due to variation in the preservation, preparation and storage of the samples, different detection methods, distinct study populations and mixed anatomical areas. In some reports, it is not clear whether the analyzed samples originate from the oral (mobile) tongue or from the base of the tongue, which is part of the oropharynx. Since oropharyngeal tumors have a different prognosis and are more likely to be HPV positive than tumors from the oral cavity, tumor localization is a fundamental survival factor in OSCC studies. This study addressed the limitations of some previous studies by focusing only on oral cavity carcinomas.

Many OSCC patients die of second PTs of the upper aerodigestive tract. Patients with HPV-associated OSCC are less prone to traditional risk factors, such as tobacco, and it is less probable that they will develop a second PT, resulting in a better prognosis for the disease $(5,44)$. The large number of non-smoking HPV-positive patients as seen in our results, might explain the better prognosis for patients with HPV infection. The small number of non-smoking patients with OSCC makes this research more difficult, resulting in few studies that describe the possible interaction between smoking and HPV infection. Additional studies are required to compare HPV status and survival among non-smokers in order to further support the notion of a favorable prognosis found in other studies. We were unable to make this comparison due to the small number of non-smoking patients.

Although we cannot rule out a possible transient role for HPV in the induction of OSCC, we think that the occasional detection of HPV in OSCC resulting from the incidental colonization of OSCC lesions might reflect the true involvement of HPV in most investigations. We suggest that other methodologies should be utilized and population studies should be performed to confirm our results. The few studied OSCC cases with detectable HPV suggest that this virus does not have the same etiological influence as tobacco consumption in these patients. However, a relative HPV contribution to oral carcinogenesis may occur in a subgroup of patients, mainly in areas where tobacco use is less common.

\section{Acknowledgements}

This research was supported by a Grant from Fundaçao de Amparo a Pesquisa do Estado de Sao Paulo (FAPESP 03/ 02532-8). The authors wish to acknowledge the technical assistance of Deisy Mara da Silva, Laura Midori Kawasse and Marcia Aparecida Ferreira Oliva. 


\section{References}

1. Miller CS and Johnstone BM: Human papillomavirus as a risk factor for oral squamous cell carcinoma: a meta-analysis, 19821997. Oral Surg Oral Med Oral Pathol Oral Radiol Endod 91: 622-635, 2001 .

2. Dahlstrom KR, Adler-Storthz K, Etzel CJ, et al: Human papillomavirus type 16 infection and squamous cell carcinoma of the head and neck in never-smokers: a matched pair analysis. Clin Cancer Res 9: 2620-2626, 2003.

3. Balaram P, Nalinakumari KR, Abraham E, Balan A, Hareendran NK, Bernard HU and Chan SY: Human papillomaviruses in 91 oral cancers from Indian betel quid chewershigh prevalence and multiplicity of infections. Int J Cancer 61: 450-454, 1995.

4. Scully C: Oral cancer; the evidence for sexual transmission. Br Dent J 199: 203-207, 2005

5. Gillison ML, Koch WM, Capone RB, et al: Evidence for a causal association between human papillomavirus and a subset of head and neck cancers. J Natl Cancer Inst 92: 709-720, 2000.

6. Mork J, Lie AK, Glattre E, et al: Human papillomavirus infection as a risk factor for squamous-cell carcinoma of the head and neck. N Engl J Med 344: 1125-1131, 2001.

7. Dahlgren L, Dahlstrand HM, Lindquist D, et al: Human papillomavirus is more common in base of tongue than in mobile tongue cancer and is a favorable prognostic factor in base of tongue cancer patients. Int J Cancer 112: 1015-1019, 2004.

8. Tachezy R, Mikysková I, Ludvíková V, et al: Longitudinal study of patients after surgical treatment for cervical lesions: detection of HPV DNA and prevalence of HPV-specific anti-bodies. Eur J Clin Microbiol Infect Dis 25: 492-500, 2006

9. Park NH, Min BM, Li SL, Huang MZ, Cherick HM and Doniger J: Immortalization of normal human oral keratinocytes with type 16 human papillomavirus. Carcinogenesis 12: 1627-1631, 1991.

10. Scheffner M, Huibregtse JM, Vierstra RD and Howley PM: The HPV-16 E6 and E6-AP complex functions as a ubiquitin-protein ligase in the ubiquitination of p53. Cell 75: 495-505, 1993.

11. Howell RE and Gallant L: Human papillomavirus type 16 in an oral squamous carcinoma and its metastasis. Oral Surg Oral Med Oral Pathol 74: 620-626, 1992.

12. Woods KV, Shillitoe EJ, Spitz MR, Schantz SP and AdlerStorthz K: Analysis of human papillomavirus DNA in ora squamous cell carcinomas. J Oral Pathol Med 22: 101-108, 1993.

13. Capone RB, Pai SI, Koch WM, et al: Detection and quantitation of human papillomavirus (HPV) DNA in the sera of patients with HPV-associated head and neck squamous cell carcinoma. Clin Cancer Res 6: 4171-4175, 2000.

14. Kosel S, Burggraf S, Mommsen J, Engelhardt W and Olgemoller B: Type-specific detection of human papillomaviruses in a routine laboratory setting - improved sensitivity and specificity of PCR and sequence analysis compared to direct hybridisation. Clin Chem Lab Med 41: 787-791, 2003.

15. Ibieta BR, Lizano M, Fras-Mendivil M, Barrera JL, Carrillo A, Ma Ruz-Godoy L and Mohar A: Human papilloma virus in oral squamous cell carcinoma in a Mexican population. Oral Surg Oral Med Oral Pathol Oral Radiol Endod 99: 311-315, 2005 .

16. Uobe K, Masuno K, Fang YR, Li LJ, Wen YM, Ueda Y and Tanaka A: Detection of HPV in Japanese and Chinese oral carcinomas by in situ PCR. Oral Oncol 37: 146-152, 2001.

17. Rivero ER and Nunes FD: HPV in oral squamous cell carcinomas of a Brazilian population: amplification by PCR. Braz Oral Res 20: 21-24, 2006.

18. Oliveira LR, Ribeiro-Silva A and Zucoloto S: Prognostic impact of p53 and p63 immunoexpression in oral squamous cell carcinoma. J Oral Pathol Med 36: 191-197, 2007.

19. Oliveira LR, Ribeiro-Silva A and Zucoloto S: Prognostic significance of p53 and p63 immunolocalisation in primary and matched lymph node metastasis in oral squamous cell carcinoma. Acta Histochem 109: 388-396, 2007.

20. Ord RA: Discussion. Primary oral squamous cell carcinoma: a review of 92 cases. J Oral Maxillofac Surg 54: 955, 1996.

21. Braakhuis BJM, Tabor MP, Leemans R, van der Waal I, Snow GB and Brakenhoff RH: Second primary tumors and field cancerization in oral and oropharyngeal cancer: molecular techniques provide new insights and definitions. Head Neck 24: 206-208, 2002.

22. Shanmugaratnam S: Histologic typing of tumors of the upper respiratory tract and ear. World Health Organization, Geneva (Switzerland), 1991.
23. Chehab FF, Doherty M, Cai SP, Kan YW, Cooper S and Rubin EM: Detection of sickle cell anaemia and thalassaemias. Nature 329: 293-294, 1987.

24. Saiki RK, Bugawan TL, Horn GT, Mullis KB and Erlich HA: Analysis of enzymatically amplified B-globin and HLA-DQ alpha DNA with allele-specific oligonucleotide probes. Nature 324: 163-166, 1986 .

25. De Roda Husman AM, Walboomers JM, van den Brule AJ, Meijer CJ and Snijders PJ: The use of general primers GP5 and GP6 elongated at their 3' ends with adjacent highly conserved sequences improves human papillomavirus detection by PCR. J Gen Virol 76: 1057-1062, 1995.

26. Bettini JS, Soares EG, Duarte G, Simoes RT and Simoes AL: PCR diagnosis of HPV in cervical biopsies of CIN and invasive neoplasia formerly diagnosed as HPV negative. Acta Cytol 47 545-549, 2003

27. Kaplan EL and Meier P: Non-parametric estimation from incomplete observations. J Am Stat Assoc 53: 457-481, 1958.

28. Kansky AA, Poljak M, Seme K, Kocjan BJ, Gale N, Luzar B and Golouh R: Human papillomavirus DNA in oral squamous cell carcinomas and normal oral mucosa. Acta Virol 47: 11-16, 2003.

29. Boy S, van Rensburg EJ, Engelbrecht S, Dreyer L, van Heerden M and van Heerden W: HPV detection in primary intra-ora squamous cell carcinomas - commensal, aetiological agent or contamination? J Oral Pathol Med 35: 86-90, 2006.

30. Kantola S, Parikka M, Jokinen K, Hyrynkangs K, Soini Y Alho OP and Salo T: Prognostic factors in tongue cancer - relative importance of demographic, clinical and histopathological factors. Br J Cancer 83: 614-619, 2000.

31. Hoffmann M, Gottschlich S, Gorogh T, Lohrey C, Schwarz E, Ambrosch $\mathrm{P}$ and Kahn T: Human papillomaviruses in lymph node neck metastases of head and neck cancers. Acta Otolaryngol 125: 415-421, 2005

32. Bouda M, Gorgoulis VG, Kastrinakis NG, et al: High-risk HPV types are frequently detected in potentially malignant and malignant oral lesions, but not in normal oral mucosa. Mod Pathol 13: 644-653, 2000

33. Hafkamp HC, Speel EJ, Haesevoets A, et al: A subset of head and neck squamous cell carcinomas exhibits integration of HPV 16/18 DNA and overexpression of p16INK4A and p53 in the absence of mutations in p53 exons 5-8. Int J Cancer 107: 394-400, 2003.

34. Nemes JA, Deli L, Nemes Z and Marton IJ: Expression of p16 (INK4A), p53 and Rb proteins are independent from the presence of human papillomavirus genes in oral squamous cell carcinoma Oral Surg Oral Med Oral Pathol Oral Radiol Endod 102: 344-352, 2006.

35. Matzow T, Boysen M, Kalantari M, Johansson B and Hagmar B Low detection rate of HPV in oral and laryngeal carcinomas. Acta Oncol 37: 73-76, 1998.

36. Cruz IB, Snijders PJ, Steenbergen RD, Meijer CJ, Snow GB, Walboomers JM and van der Waal I: Age-dependence of human papillomavirus DNA presence in oral squamous cell carcinomas Eur J Cancer B Oral Oncol 32B: 55-62, 1996.

37. Zhang ZY, Sdek P, Cao J and Chen WT: Human papillomavirus type 16 and 18 DNA in oral squamous cell carcinoma and normal mucosa. Int J Oral Maxillofac Surg 33: 71-74, 2004.

38. Schwartz SR, Yueh B, McDougall JK, Daling JR and Schwartz SM: Human papillomavirus infection and survival in oral squamous cell cancer: a population-based study. Otolaryngol Head Neck Surg 125: 1-9, 2001.

39. Ritchie JM, Smith EM, Summersgill KF, et al: Human papillomavirus infection as a prognostic factor in carcinomas of the oral cavity and oropharynx. Int J Cancer 104: 336-344, 2003.

40. Fouret P, Monceaux G, Temam S, Lacourreye L and St Guily JL: Human papillomavirus in head and neck squamous cell carcinomas in non-smokers. Arch Otolaryngol Head Neck Surg 123 513-516, 1997

41. Herrero R, Castellsague X, Pawlita M, et al: Human papillomavirus and oral cancer: the International Agency for Research on Cancer multicenter study. J Natl Cancer Inst 95: 1772-1783, 2003.

42. Chellemi SJ, Olson DL and Shapiro S: The association between smoking and aphthous ulcers. A preliminary report. Oral Surg Oral Med Oral Pathol 29: 832-836, 1970.

43. Chiba I, Shindoh M, Yasuda M, et al: Mutations in the p53 gene and human papillomavirus infection as significant prognostic factors in squamous cell carcinomas of the oral cavity. Oncogene 12: $1663-1668,1996$.

44. Koch WM, Lango M, Sewell D, Zahurak M and Sidransky D: Head and neck cancer in non-smokers: a distinct clinical and molecular entity. Laryngoscope 109: 1544-1551, 1999. 